Article

\title{
Congruence Evaluation of Mercury Pollution Patterns Around a Waste Incinerator over a 16-Year-Long Period Using Different Biomonitors
}

\author{
Lorenzo Fortuna $^{1}{ }^{\mathbb{D}}$, Fabio Candotto Carniel ${ }^{1} \mathbb{1}$, Fiore Capozzi ${ }^{2} \mathbb{D}$ and Mauro Tretiach ${ }^{1, *}$ \\ 1 Department of Life Sciences, University of Trieste, Via Licio Giorgieri, 10, 34127 Trieste, Italy; \\ lfortuna@units.it (L.F.); fcandotto@units.it (F.C.C.) \\ 2 Department of Biology, University of Naples Federico II, Italy, Cupa Nuova Cintia, 21, 80126 Napoli, Italy; \\ fiore.capozzi@unina.it (F.C.) \\ * Correspondence: tretiach@units.it (M.T.)
}

Received: 28 February 2019; Accepted: 2 April 2019; Published: 5 April 2019

\begin{abstract}
To date, there has been an ever-increasing interest in complementary air monitoring techniques, which may fill the deficiencies of air quality networks. The present work reports the results concerning five biomonitoring surveys (BSs) performed in the proximity of a waste incinerator (WI) over a 16-year period. Hg emission related to the WI activity was monitored by means of both active and passive BSs based on three photosynthetically-active biomonitors (i.e., two epiphytic lichens: Pseudevernia furfuracea and Xanthoria parietina; one vascular plant: Robinia pseudoacacia) collected or exposed before and / or after the WI installation, and after a four-month period of inactivity. $\mathrm{Hg}$ concentration values observed in biomonitor samples varied according to the implemented species and to the status of WI plant (active vs. inactive). Our data demonstrate that, in the same pollution scenario, P. furfuracea accumulates three times more $\mathrm{Hg}$ than both X. parietina and R. pseudoacacia. The results are discussed in the context of the actual European Union directives concerning air pollution monitoring and assessment, revealing that both active and passive BSs are efficient tools to provide a reliable estimation of the spatial changes of $\mathrm{Hg}$ concentrations in the environment.
\end{abstract}

Keywords: biomonitor; Hg pollution; Pseudevernia furfuracea; Robinia pseudoacacia; waste incinerator; Xanthoria parietina

\section{Introduction}

Mercury $(\mathrm{Hg})$ represents a severe threat to human health and the environment as both atmospheric elemental mercury $\left(\mathrm{Hg}^{0}\right)$ and methylmercury accumulate through the aquatic and terrestrial food webs. Owing to its toxicity and long-range transport, $\mathrm{Hg}$ pollution has long been recognized as a global issue [1]. Many international efforts have been spent at developing legally-binding treaties (see the work of [2]) in order to reduce $\mathrm{Hg}$ emission in the environment [3]. In Europe, the current air quality directives state the need to reduce $\mathrm{Hg}$ emissions by regulating the industrial activities through integrated pollution prevention and control programs and, in parallel, by improving air quality monitoring and assessment programs [4-7]. To date, $\mathrm{Hg}$ air pollution has mainly been assessed at the continental and global level by carrying out punctual measurements with manual or automated air quality monitoring stations [8], applying highly standardized physical-chemical methodologies, defined at legislative level [4]. However, because of the high costs related to elemental analysis of bulk deposition, the monitoring networks of atmospheric $\mathrm{Hg}$ are still characterized by a low spatial and temporal coverage. For instance, in the European Union (EU), only $14 \%$ of national air pollution monitoring networks provide air concentration data for this element on an annual basis [9]. Therefore, 
there is an ever-increasing interest in complementary air monitoring techniques, which may fill the deficiencies of the extant air quality networks by providing reliable time-integrated estimations of air pollution in a given area $[10,11]$.

An example of a less expensive, but reliable alternative to the direct measurement of air and/or particulate matter (PM) is given by the use of plant biomonitors [12], which can provide a spatial, time-integrated assessment of $\mathrm{Hg}$ pollution. Both vascular plants and cryptogams, like lichens and mosses, have been successfully used as $\mathrm{Hg}$ bioaccumulators [13]. Although studies have mainly focused on comparing the performances of allochthonous biomonitors in accumulating air pollutants [14-17], there is still a lack of studies specifically aimed at comparing the results of biomonitoring surveys (BSs) carried out in the same pollution scenario, but using different biomonitors.

The present work reports the results of one of the longest biomonitoring studies of $\mathrm{Hg}$ air pollution ever carried out at a local scale. The data presented herein concern five BSs performed in the proximity of a waste incinerator (WI) over a 16-year period according to both active (biomonitor transplants) and passive (sampling native biomonitor populations) techniques.

The aim of this work is (a) to provide an overview about the efficiency of different organisms as biomonitors of $\mathrm{Hg}$ pollution within the same pollution scenario, and (b) to test the effectiveness of both passive and active biomonitoring techniques in tracking $\mathrm{Hg}$ emission from a point source. The results are also discussed in relation to the European Union directives, revealing that BSs, when properly planned and executed, are efficient tools, which provide reliable estimation of the spatial-temporal changes of $\mathrm{Hg}$ concentrations in the environment.

\section{Material and Methods}

\subsection{Study Area}

The study area is located in the Friulian floodplain (NE Italy), circa $10 \mathrm{~km}$ south of the Carnic pre-Alps (Figure 1a). The climate is relatively rainy $(1500 \mathrm{~mm} /$ year) and temperate, with cold winters and warm summers mitigated by frequent thunderstorms. North-blowing winds prevail in the western portion, whereas southwestern winds prevail, especially during night, in the eastern portion [18]. The land use of the study area is relatively homogeneous and is characterized as follows: $70 \%$ is covered by corn, soy bean and vineyard fields, highly specialized grape nurseries, and stable meadows; $16 \%$ by natural vegetation, restricted to the two river banks that mark off the study area east- and westward (Tagliamento and Meduna, respectively); and the remaining 14\% is covered by industrial and urban settlements, the largest one being Spilimbergo, with circa 10,000 inhabitants. The industrial activities are small manufactures mainly concentrated in two industrial zones, or scattered in the territory, intermingled with the urban fabric (Figure 1b).

The waste incinerator (WI), located SW of the town of Spilimbergo, was built in 1978, closed in 1985, and rebuilt in 1999. In 2002, the authorization was renewed in order to implement the total quantity of disposable waste at 25,000 tons year ${ }^{-1}$. The WI incinerates wastes at $980-1300{ }^{\circ} \mathrm{C}$, and related pollutant emissions are mitigated by fabric filters; flue gas flow is approximately $10.25 \mathrm{Nm}^{3} \mathrm{~s}^{-1}$ at $192{ }^{\circ} \mathrm{C}$ from a $23 \mathrm{~m}$ high stack. In Italy, the legislative limit threshold for $\mathrm{Hg}$ emission is $0.05 \mathrm{mg} \mathrm{Nm}^{-3}$ [D.M. 25 February 2000, n. 124; http:/ /www.gazzettaufficiale.it/eli/id/2000/05/18/000G0171/sg] and the actual emission value is certified quarterly by a private company. 

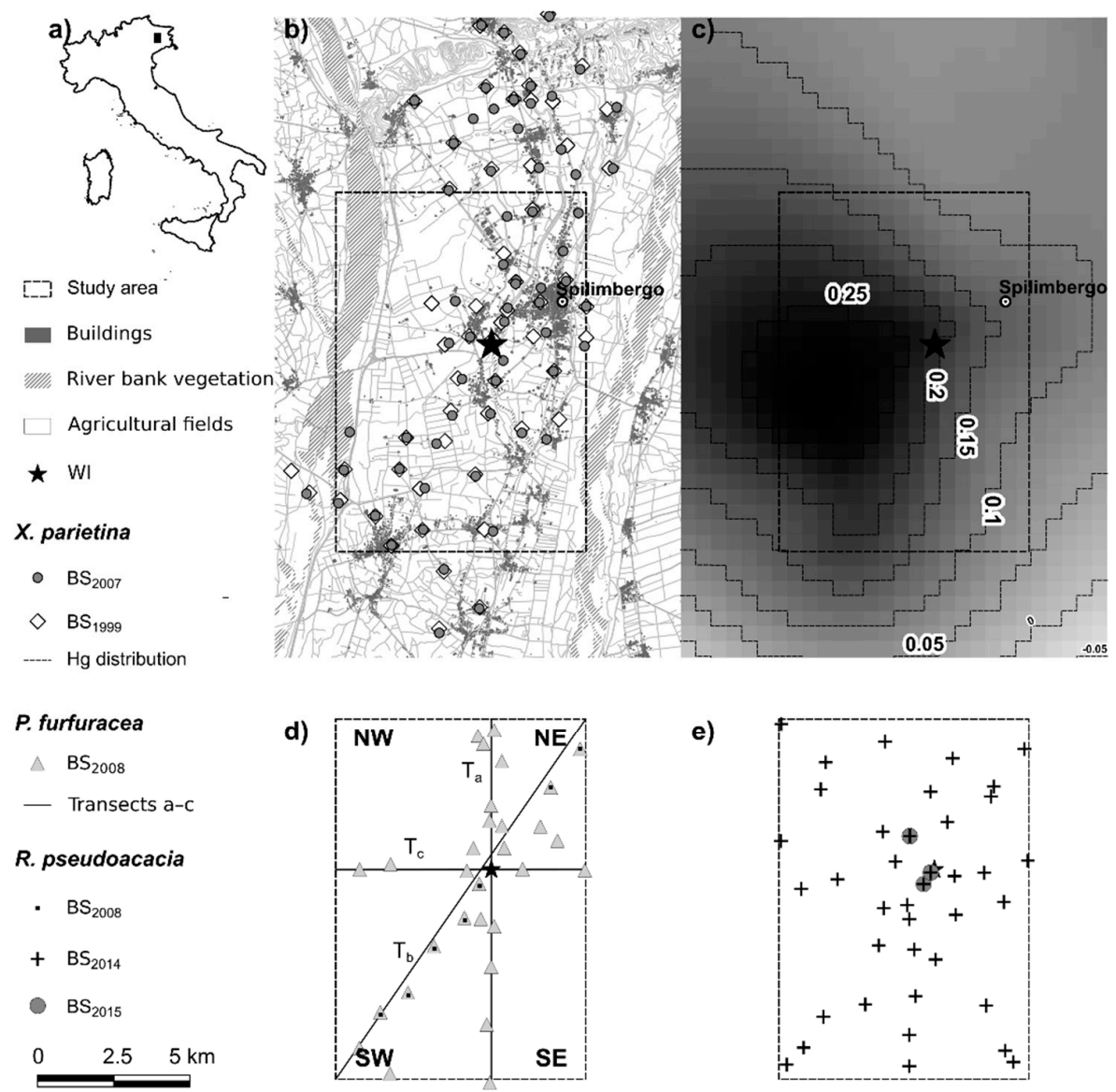

Figure 1. (a) Location of the study area; (b) cartographic details of the study area with the sampling sites of the epiphytic lichen Xanthoria parietina collected in 1999 (diamonds) and 2007 (dark grey dots); (c) mercury ( $\mathrm{Hg}$ ) distribution in X. parietina samples collected in 2007; (d) line transect design (continuous lines), exposure sites of transplants of the epiphytic lichen Pseudevernia furfuracea (light grey triangles), and sampling sites of Robinia pseudoacacia leaves (little black squares), carried out in 2008; (e) sampling sites of R. pseudoacacia leaves collected in 2014 (crosses) and 2015 (grey circles). BS-biomonitoring survey; WI-Waste incinerator.

\subsection{Biomonitoring Surveys}

This work summarizes the results of five biomonitoring surveys (BSs) based on two epiphytic lichens, that is, Pseudevernia furfuracea (L.) Zopf var. furfuracea and Xanthoria parietina (L.) Th.Fr., and on the leaves of Robinia pseudoacacia L. (black locust tree). The first two surveys were carried out just before (1999) and eight years after (2007) the WI installation, respectively. These two surveys (herein named $\mathrm{BS}_{1999}$ and $\mathrm{BS}_{2007}$ ) were based on the autochthonous foliose lichen X. parietina sampled around the WI according to a random sampling design, in 56 and 64 sites (Figure 1b), respectively, with $73 \%$ of sampling sites visited in both surveys.

In 2008, a portion of $97 \mathrm{~km}^{2}$ of the original study area was subjected to a lichen transplant survey, aimed at (i) verifying whether the $\mathrm{Hg}$ pollution highlighted by $\mathrm{BS}_{2007}$ was still present, and (ii) identifying the source. In this case, the epiphytic fruticose lichen P. furfuracea was collected in a remote area (see the work of [18] for details) and exposed for 6, 12, and 24 weeks at 30 sites, 11 of which were selected in urban $(n=6)$ and industrial $(n=5)$ areas, whereas the remaining 19 were selected in agricultural areas. The exposure design was based on three transects $\left(\mathrm{T}_{\mathrm{a}-\mathrm{c}}\right)$ defined according to the following: (i) the results of $\mathrm{BS}_{2007}$ (Figure 1c); (ii) the wind frequency distribution as recorded in three nearby meteorological stations (Figure 1d; see [18]); and (iii) the location of the putative source, that is, the WI plant. 
The sampling of R. pseudoacacia leaves was carried out in three out of the five biomonitoring surveys presented in this work: in 2008, during the ongoing of sample exposure of P. furfuracea transplants (i.e., $\mathrm{BS}_{2008}$; Figure 1d), and in October 2014 and 2015 (namely $\mathrm{BS}_{2014}$ and $\mathrm{BS}_{2015}$, respectively; Figure 1e). The first leaf sampling was carried out 2 weeks before the end of the 24-week exposure period selected for P. furfuracea transplants (see above). In this case, R. pseudoacacia leaf samples were collected at eight exposure sites from twigs immediately adjacent to the lichen transplants exposed along $\mathrm{T}_{\mathrm{b}}$, that is, the portion of the study area where $P$. furfuracea samples had the highest $\mathrm{Hg}$ concentrations after both 6 and 12 weeks. In 2014, the sampling of $R$. pseudoacacia leaves was iterated at the above mentioned 8 sites and extended to a further 31 sites (total sites $n=39$ ), whose location corresponded as much as possible to the exposure sites selected for the lichen transplant survey (compare Figure 1d with Figure 1e). In July 2015, the WI activity was shut down for an internal incident. After a non-operative period of four months, the sampling of R. pseudoacacia leaves was repeated at three sites of $\mathrm{BS}_{2014}$ (Figure 1e) located in the immediate proximity of the WI.

\subsection{Sample Treatments}

Lichen and plant material was pre-treated (cleaning and material selection) and homogenized by manual or automated powdering according to accepted and well-known protocols commonly used in biomonitoring surveys $[12,19]$. More details about the preparation of analytical samples are reported in Supplementary Material SM1.1-SM1.3.

\subsubsection{Characterization of Robinia pseudoacacia Leaf Samples}

The 2014 sampling of R. pseudoacacia leaves was carried out at the end of the vegetative season, when the pigmentation of collected leaves was highly heterogeneous among and within samples. Hence, in order to test whether different leaf pigmentation was related to differences in $\mathrm{Hg}$ accumulation, subsamples of yellow $(\mathrm{Y})$ and green $(\mathrm{G})$ leaves collected at eight sites were separately pre-treated for $\mathrm{Hg}$ analyses, as explained in Supplementary Material SM 1.3. At the same time, the average specific leaf area (SLA) of $Y$ and G leaves was assessed on 10 randomly selected sub-samples of circa $600 \mathrm{mg}$ each. SLA was measured according to the method reported in the work of [20].

\subsection{Mercury Analysis}

Overall, nine series of samples relating to three different biomonitors, that is, X. parietina, P. furfuracea, and R. pseudoacacia, were collected. Hereinafter, in order to refer to a specific series of samples the notation reported in Table 1 is used.

Prior to $\mathrm{Hg}$ analysis, $\mathrm{Xp}_{1999}$ and $\mathrm{Xp}_{2007}$ (Table 1) samples were digested in Teflon bombs with $2.5 \mathrm{~mL}$ of $\mathrm{HNO}_{3} 65 \%(\mathrm{v} / \mathrm{v})$ at $120^{\circ} \mathrm{C}$ (herein, "partial acid digestion"). $\mathrm{Hg}$ content of mineralized $\mathrm{X}_{1999}$ and $\mathrm{X}_{2007}$ samples was measured by means of cold vapor atomic absorption (CVAA) and inductively coupled plasma mass spectrometry (ICP-MS), respectively. Both sets of analyses were carried out at the laboratories of the University of Siena under the supervision of Prof. R. Bargagli. On the other hand, lichen and leaves samples collected in 2008 (i.e., Pf-6-12-24 2008 and $\mathrm{Rp}_{2008}$; see Table 1) were digested in Teflon bombs with $6 \mathrm{~mL} \mathrm{HNO}_{3} 65 \%(v / v), 0.2 \mathrm{~mL} \mathrm{HF} \mathrm{50 \%}(v / v)$, and $1 \mathrm{~mL}$ $\mathrm{H}_{2} \mathrm{O}_{2} 30 \%(v / v)$ (herein, "total acid digestion") in a microwave oven with stepwise power application. In this case, the $\mathrm{Hg}$ content in mineralized leaves and lichen samples was measured by flow injection mercury system (FIMS) at the laboratory of the Regional Agency Environmental Protection of Friuli Venezia Giulia (ARPA FVG). Hg concentrations in Rp- $\mathrm{G}_{2014}, \mathrm{Rp}-\mathrm{Y}_{2014}$, and $\mathrm{Rp}_{2015}$ (Table 1) samples were analyzed by direct mercury analysis (DMA-80, Milestone, Brondby Kommune, Denmark) at the laboratories of the University of Compostela, under the supervision of Prof. Fernández Escribano. Elemental $\mathrm{Hg}$ analyses were always determined by comparison with standard solutions. $\mathrm{Hg}$ content in procedural blanks was always below the detection limit. The accuracy of digestion and analytical procedures was checked by routine determination of element concentrations in standard reference material (Table S1 in Supplementary Materials). 
Table 1. Notation used to name the nine sample series analyzed in this work. The notation used refers to the following: (i) biomonitor species (Xp: X. parietina; Pf: P. furfuracea; Rp: R. pseudoacacia); (ii) exposure period (i.e., 6, 12, or 24 weeks; See Section 2.2) or, alternatively, to the pigmentation of sampled leaves (i.e., green-G; yellow-Y; see Section 2.3.1); and (iii) year of sampling (i.e., 1999, 2007, 2008, 2014, and 2015). P: passive technique; A: active technique.

\begin{tabular}{cccc}
\hline Series of Samples & Technique & Year & Biomonitor \\
\hline $\mathrm{Xp}_{1999}$ & $\mathrm{P}$ & 1999 & X. parietina, native \\
$\mathrm{Xp}_{2007}$ & $\mathrm{P}$ & 2007 & X. parietina, native \\
$\mathrm{Pf}-\mathrm{6}_{2008}$ & $\mathrm{~A}$ & 2008 & P. furfuracea, transplants \\
$\mathrm{Pf}-2_{2008}$ & $\mathrm{~A}$ & 2008 & P. furfuracea, transplants \\
$\mathrm{Pf}-24_{2008}$ & $\mathrm{~A}$ & 2008 & P. furfuracea, transplants \\
$\mathrm{Rp}_{2008}$ & $\mathrm{P}$ & 2008 & Green leaves of $R$. pseudoacacia, native \\
$\mathrm{Rp}_{2014} \mathrm{G}_{201}$ & $\mathrm{P}$ & 2014 & Green leaves of $R$. pseudoacacia, native \\
$\mathrm{Rp}_{2} \mathrm{Y}_{2014}$ & $\mathrm{P}$ & 2014 & Yellow leaves of $R$. pseudoacacia, native \\
$\mathrm{Rp}_{2015}$ & $\mathrm{P}$ & 2015 & Green leaves of $R$. pseudoacacia, native \\
\hline
\end{tabular}

\subsection{Data Analysis}

Basic descriptive statistics were calculated for each of the nine series of samples. In order to take into account the effect of the wind regime on the dispersion of WI emissions, both sampling and exposure sites were classified according to their relative position with respect to the WI plant (Figure 1d). Significant increases of $\mathrm{Hg}$ concentration values among different series of X. parietina or P. furfuracea samples were assessed with a generalized linear model (GLM), assuming the year of sampling or exposure period along with the wind regime as categorical predictors, whereas the distance of the sampling/exposure sites from the WI was assumed as a continuous predictor.

Among the BSs based on R. pseudoacacia, there was a high discrepancy in terms of the number of collected samples. Therefore, the significant temporal increase or decrease of $\mathrm{Hg}$ concentrations in samples leaves was tested with the Mann-Whitney non-parametric test for paired samples. The comparison of the medians was performed between (i) samples collected along $T_{b}$ in $2008\left(R_{2} p_{2008}\right.$; $\mathrm{n}=8$ ) and 2014 (a subset of $\mathrm{Rp}-\mathrm{G}_{2014} ; \mathrm{n}=10$ ), and (ii) samples collected in 2014 (a subset of Rp- $\mathrm{G}_{2014}$; $\mathrm{n}=9)$ and $2015\left(\mathrm{Rp}_{2015} ; \mathrm{n}=9\right)$ in the immediate proximity of the WI.

Trends of $\mathrm{Hg}$ concentration in each series of biomonitor samples were analyzed according to the distance of sampling/exposure sites from the WI (i.e., trend analysis). Furthermore, the difference between $\mathrm{Hg}$ content of Rp- $\mathrm{G}_{2014}$ and Rp- $\mathrm{Y}_{2014}$ samples expressed as a function of SLA was tested by means of a T-test for paired samples.

The results of BSs obtained with different biomonitors were compared depending on the spatial distribution of $\mathrm{Hg}$ content measured in six out of the nine series of samples (i.e., $\mathrm{Xp}_{1999}, \mathrm{Xp}_{2007}$, Pf- $6_{2008}$, Pf-12 2008 , Pf-24 2008 , and Rp-G 2014 ). Spatial distribution maps were calculated according to ordinary Kriging interpolation algorithms [21]. Both setting parameters and variogram function selected for interpolation analysis are reported in Table S2. The local variability of predicted values (i.e., interpolated values) was expressed as the variance of $\mathrm{Hg}$ concentrations [22], whereas their accuracy was expressed as the root mean square error (RMSE) measured between observed and interpolated values [23]. Finally, in order to evaluate the consistency among the six spatial distribution patterns, the degree of correlation among the interpolated values was investigated at 250 randomly selected points selected within the spatial domain of the study area.

\section{Results}

Table 2 reports basic descriptive statistics of $\mathrm{Hg}$ content measured in the nine series of samples collected in the BSs carried out before (i.e., $\mathrm{BS}_{1999}$ ) and after (i.e., $\mathrm{BS}_{2007}, \mathrm{BS}_{2008}$, and $\mathrm{BS}_{2014}$ ) the WI implanting (2000), and during the non-operational period of the plant $\left(\mathrm{BS}_{2015}\right)$. Minimum, average, and maximum $\mathrm{Hg}$ concentration values observed among BSs differed according to the following: (i) year of sampling, (ii) biomonitor, and (iii) status of the WI plant (active vs. inactive). 
Table 2. Basic descriptive statistics of $\mathrm{Hg}$ content measured in the nine series of biomonitor samples collected between 1999 and 2015. Exposure period for the epiphytic lichen Xanthoria parietina and the leaves of Robinia pseudoacacia were estimated according to the works of [24,25]; those of the transplanted lichen Pseudevernia furfuracea were taken from the work of [19]. WI: waste incinerator; on: WI active; off: WI inactive; BS: biomonitoring survey; n: number of exposed or collected samples; Min, Max, Mean: minimum, maximum and mean $\mathrm{Hg}$ concentration value; $\mathrm{St}$. dev.: standard deviation; $\mathrm{CV} \%$ : percent variation coefficient.

\begin{tabular}{|c|c|c|c|c|c|c|c|c|c|}
\hline \multirow{3}{*}{$\begin{array}{c}\text { Parameters } \\
\text { WI status } \\
\text { BS }\end{array}$} & \multicolumn{2}{|c|}{ X. parietina } & \multicolumn{3}{|c|}{ P. furfuracea } & \multicolumn{4}{|c|}{ R. pseudoacacia } \\
\hline & off & on & & on & & on & Or & & off \\
\hline & $\mathrm{BS}_{1999}$ & $\mathrm{BS}_{2007}$ & & $\mathrm{BS}_{2008}$ & & $\mathrm{BS}_{2008}$ & $\mathrm{BS}_{2}$ & & $\mathrm{BS}_{2015}$ \\
\hline Sample Series & $\mathrm{Xp}_{1999}$ & $\mathrm{Xp}_{2007}$ & Pf- $6_{2008}$ & Pf $-12_{2008}$ & Pf-24 2008 & $\mathrm{Rp}_{2008}$ & $\mathrm{Rp}-\mathrm{G}_{2014}$ & $R p-Y_{2014}$ & $\mathrm{Rp}_{2015}$ \\
\hline Exposure Period (Weeks) & $\sim 52$ & $\sim 52$ & 6 & 12 & 24 & $\sim 40$ & $\sim 40$ & $\sim 40$ & $\sim 40$ \\
\hline $\mathrm{n}$ & 56 & 64 & 30 & 30 & 30 & 8 & 39 & 8 & 3 \\
\hline Min & 0.011 & 0.039 & 0.130 & 0.150 & 0.130 & 0.000 & 0.017 & 0.024 & 0.023 \\
\hline Max & 0.270 & 0.384 & 4.370 & 5.130 & 5.000 & 0.360 & 0.326 & 0.425 & 0.061 \\
\hline Mean & 0.096 & 0.141 & 0.371 & 0.467 & 0.500 & 0.135 & 0.052 & 0.106 & 0.040 \\
\hline St. dev. & 0.064 & 0.078 & 0.764 & 0.899 & 0.919 & 0.126 & 0.052 & 0.135 & 0.019 \\
\hline $\mathrm{CV} \%$ & 66.6 & 55.5 & 206.0 & 192.5 & 183.9 & 93.6 & 101.0 & 126.7 & 47.4 \\
\hline
\end{tabular}

Both GLM analyses revealed that the increase of $\mathrm{Hg}$ content in autochthonous and transplanted lichens were significantly related to the distance of sampling/exposure sites from the WI (Table 3; Figure 2a). The relationship between $\mathrm{Hg}$ concentrations in both lichen and leaf samples and the distance of the sampling/exposure sites from the WI were described according to a power or an exponential function (Figure 2a). The GLM-based comparison between Hg bioaccumulation data of the first two BSs $\left(\mathrm{BS}_{1999}\right.$ and $\mathrm{BS}_{2007}$ ) revealed a significant increase of $\mathrm{Hg}$ concentration in X. parietina native thalli, especially in sites located SW of the WI (Figure 2b). According to this, the interaction term between the year of sampling and the wind regime is highly significant (Table 3).

Table 3. Generalized linear model (GLM) summary statistics performed on Hg concentration values observed in samples of the lichens Xanthoria parietina (autochthonous) and Pseudevernia furfuracea (transplanted) collected or exposed in the study area during the respective biomonitoring surveys (see text). SS: sum of squares; MS: mean squares; F: F-statistic; p: p-value. Significant effect of continuous or categorical predictors are reported in bold

\begin{tabular}{ccccc}
\hline & SS & MS & F & $p$ \\
\hline X. parietina & & & & \\
Intercept & 0.50 & 0.50 & 136.64 & $<\mathbf{0 . 0 0 1}$ \\
Distance (D) & 0.02 & 0.02 & 5.93 & $\mathbf{0 . 0 1 6}$ \\
Year (Y) & 0.05 & 0.05 & 13.01 & $<\mathbf{0 . 0 0 1}$ \\
Wind (W) & 0.02 & 0.01 & 2.15 & 0.098 \\
Y $\times$ W & 0.16 & 0.05 & 14.23 & $<\mathbf{0 . 0 0 1}$ \\
Error & 0.41 & 0.00 & & \\
Total & 0.67 & & & \\
Model & 0.26 & 0.03 & 8.72 & $<\mathbf{0 . 0 0 1}$ \\
\hline P. furfuracea & & & & \\
Intercept & 18.21 & 18.21 & 30.50 & $<\mathbf{0 . 0 0 1}$ \\
D & 10.40 & 10.40 & 17.41 & $<\mathbf{0 . 0 0 1}$ \\
Exposure (E) & 0.16 & 0.08 & 0.13 & 0.877 \\
W & 13.37 & 4.46 & 7.46 & $<\mathbf{0 . 0 0 1}$ \\
E $\times$ W & 0.23 & 0.04 & 0.06 & 0.998 \\
Error & 44.19 & 0.60 & & \\
Total & 62.60 & & & \\
Model & 18.41 & 1.53 & 2.57 & $<\mathbf{0 . 0 0 1}$ \\
\hline
\end{tabular}



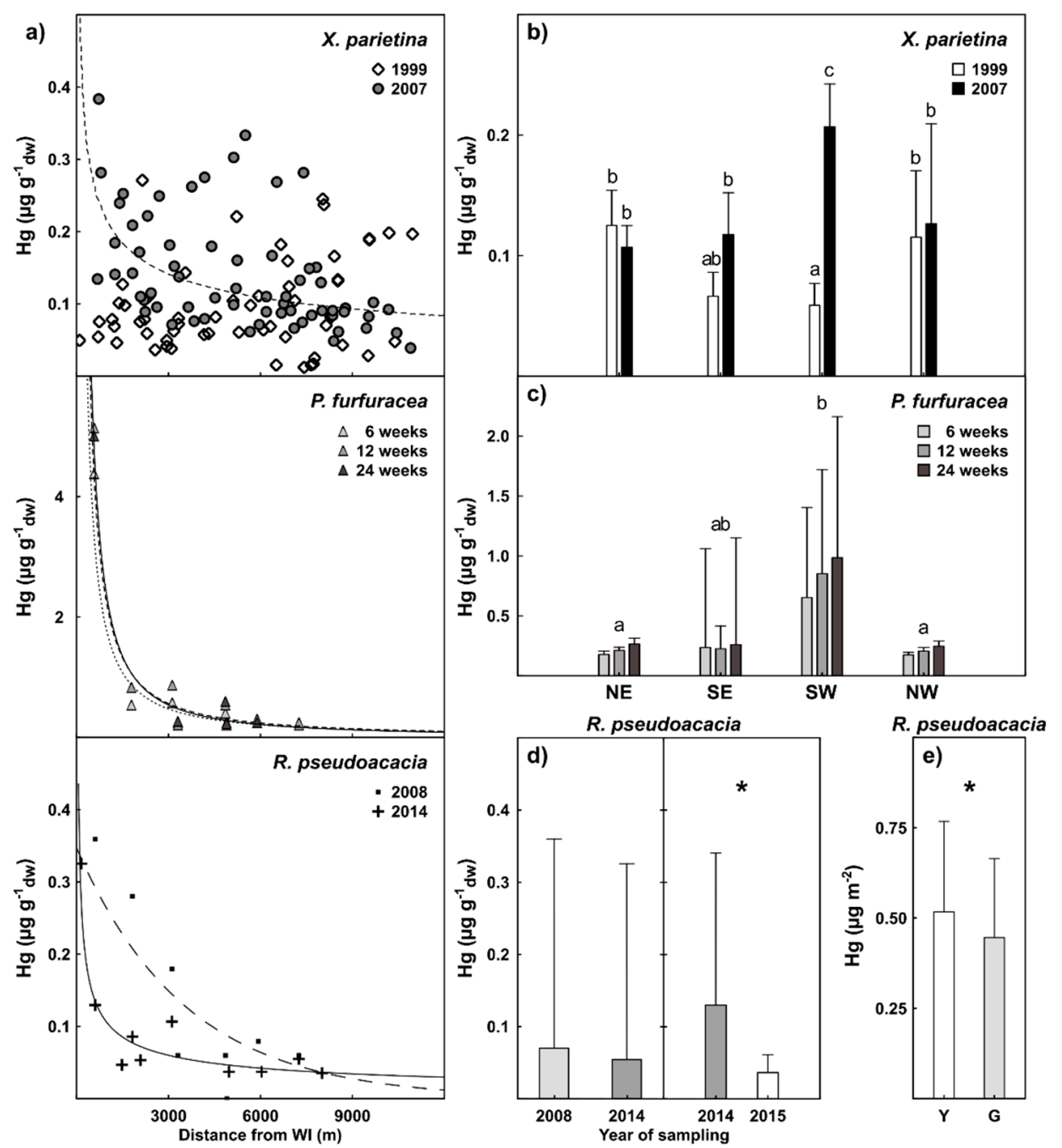

Figure 2. (a) Trends of $\mathrm{Hg}$ concentration vs. distance of exposure or sampling sites from the WI; $(\mathbf{b}, \mathbf{c})$ results of generalized linear model (GLM)-based comparison performed on samples of the lichens Xanthoria parietina and Pseudevernia furfuracea (see Section 2.5; data elaborated from the work of [18]); (d) median comparison between leaves of Robinia pseudoacacia sampled in 2008 and 2014 in the whole study area and in 2014 and 2015 in three sites close to the WI (see text for explanation); (e) comparison of $\mathrm{Hg}$ content in yellow $(\mathrm{Y})$ and green $(\mathrm{G})$ R. pseudoacacia leaves collected in the same ten sites in 2014. Different letters in $(\mathbf{b}, \mathbf{c})$, as well as asterisks in $(\mathbf{d}, \mathbf{e})$, indicate significant difference for $p<0.05$.

The results of the following BSs strengthened the findings of the 2007 survey, indicating that the $\mathrm{Hg}$ pollution was not the result of a stochastic episode. The GLM analysis of the $\mathrm{BS}_{2008}$ data showed a significant high He enrichment in P. furfuracea samples exposed SW of the WI (Figure 2c), with values that are still the highest ever observed in biomonitoring surveys with $P$. furfuracea transplants (see the works of [26-28]). Nevertheless, there were no significant differences among the three selected exposure periods (Table 3; Figure 2c), although the Hg enrichment pattern was the same in all three series of transplanted samples (i.e., those exposed for 6, 12, and 24 weeks), clearly pointing out a close relationship between wind regime of the study area and WI location.

The result of the Mann-Whitney-based comparisons between the $\mathrm{Rp}_{2008}$ and $\mathrm{Rp}-\mathrm{G}_{2014}$ samples was not significant, revealing that the load of $\mathrm{Hg}$ pollution in the study area did not decrease between 2008 and 2014 (Figure 2d). Along the transect Tb of Figure 1d, the Hg content of R. pseudoacacia leaves in 2014 was still strictly related to the distance from the WI. However, the Hg concentration trend in R. pseudoacacia leaves collected in 2014 was slightly different to that observed in leaves collected in 2008 (Figure 2d), possibly for the different analytical techniques (in 2008: FIMS; percent recovery: 
$100 \%$; in 2014: DMA; percent recovery from $80 \%$ to $115 \%$ ). Interestingly, a significant decrease of $\mathrm{Hg}$ content was observed in R. pseudoacacia leaves collected in October 2015, four months after the WI had been shut down as a consequence of an accident (Figure 2d). Therefore, by sampling R. pseudoacacia leaves during this non-operative period in 2015, it was possible to incontrovertibly demonstrate that the WI activity was significantly related to the fluctuation of $\mathrm{Hg}$ content observed in $\mathrm{R}$. pseudoacacia leaves (Figure 2d).

The spatial distribution maps of $\mathrm{Hg}$ content in the biomonitor samples are reported in Figure 3. Overall, the interpolation values calculated for six out of the nine series of biomonitor samples (i.e., $\mathrm{Xp}_{1999}, \mathrm{Xp}_{2007}, \mathrm{Pf}-6_{2008}, \mathrm{Pf}-\mathbf{1 2}_{2008}, \mathrm{Pf}-\mathbf{2 4}_{2008}$, and Rp- $\mathrm{G}_{2014}$ ) were predicted with a more than satisfactory accuracy (RMSE between the $0.009 \mu \mathrm{g} \mathrm{g}^{-1}$ of $\mathrm{Rp}_{2014}$ samples to the $0.3375 \mu \mathrm{g} \mathrm{g}^{-1}$ of Pf $6_{2008}$ samples) and with a low local variability (Table 4). Most importantly, the correlation analysis among the six series of interpolated values (see Section 2.5) revealed a good spatial consistency, with highly significant values of Pearson's $r$ correlation coefficient among the bioaccumulation data collected between 2007 and 2014 (Table 4).

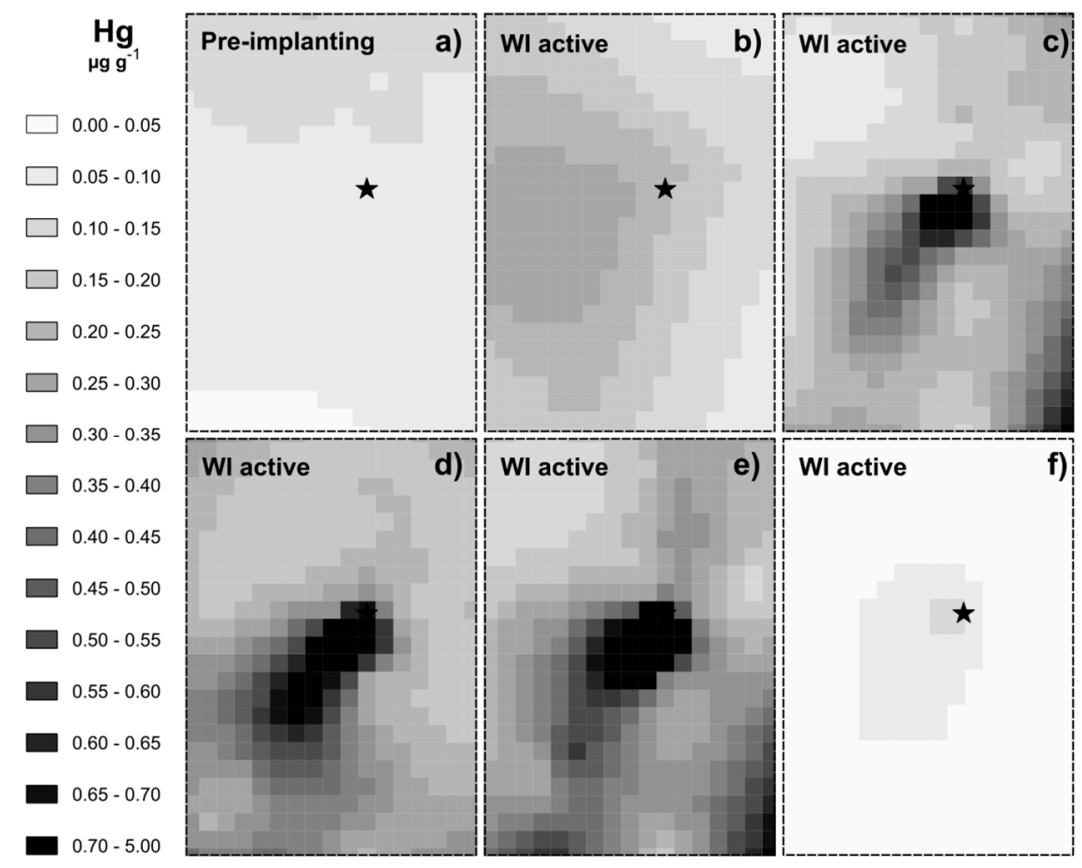

Figure 3. Result of kriging interpolation analyses based on (a) $\mathrm{X}_{1999}$, (b) $\mathrm{X}_{2007}$, (c) Pf-6 $\mathrm{C}_{2008}$, (d) Pf-12 2008 , (e) Pf-24 2008 , and (f) Rp- $\mathrm{G}_{2014}$ samples. The notation of samples is reported in Section 2.4.

Table 4. Summary of interpolation analyses carried out on $\mathrm{Xp}_{1999}, \mathrm{X}_{2007}, \mathrm{Pf}-6_{2008}, \mathrm{Pf}-12_{2008}, \mathrm{Pf}-24_{2008}$, and $R p-G_{2014}$ datasets. RMSE and VAR are expressed in $\mu \mathrm{g} \mathrm{g}^{-1}$ and correspond to the root mean square error and the local variability, respectively. Significant correlation values among interpolated values are reported in bold.

\begin{tabular}{|c|c|c|c|c|c|c|c|c|}
\hline Set of Samples & RMSE & Variance Range & $X p_{1999}$ & $\mathrm{Xp}_{2007}$ & $P f-6_{2008}$ & Pf-12008 & Pf-24 2008 & $R p-G_{2014}$ \\
\hline $\mathrm{Xp}_{1999}$ & 0.0315 & $\simeq 0$ & 1 & & & & & \\
\hline $\mathrm{Xp}_{2007}$ & 0.0345 & {$[0.002,0.003]$} & -0.054 & 1 & & & & \\
\hline Pf-6 2008 & 0.3375 & {$[0.029,0.247]$} & -0.220 & 0.023 & 1 & & & \\
\hline Pf- $12_{2008}$ & 0.0892 & {$[-0.124,0.122]$} & -0.218 & 0.327 & 0.90 & 1 & & \\
\hline Pf-24 2008 & 0.334 & {$[-0.176,0.663]$} & -0.271 & 0.121 & 0.970 & 0.934 & 1 & \\
\hline $\mathrm{Rp}-\mathrm{G}_{2014}$ & 0.0093 & {$[0.017,0.152]$} & -0.341 & 0.546 & 0.546 & 0.662 & 0.616 & 1 \\
\hline
\end{tabular}




\section{Discussion}

\subsection{The Pattern of Hg Pollution}

Waste incinerators have frequently been associated with $\mathrm{Hg}$ emission by means of both biomonitor surveys [29] and direct instrumental records [30]. In the Mediterranean basin, WI plants are estimated to emit in the atmosphere approximately $16.6 \mathrm{t} \mathrm{yr}^{-1} \mathrm{of} \mathrm{Hg}^{2+}, 5.5 \mathrm{t} \mathrm{yr}^{-1}$ of particulate $\mathrm{Hg}\left(\mathrm{Hg}_{\mathrm{p}}\right)$, and $16.6 \mathrm{t} \mathrm{yr}^{-1}$ of $\mathrm{Hg}^{0}$ [31]. By-products of waste incineration, for example, slug (mostly used for road construction, noise barriers, concrete production, or landfill material), could contain relatively high quantities of $\mathrm{Hg}$ (from 0.02 to $7.75 \mathrm{mg} \mathrm{kg}^{-1}$ ), which can be partially released into the atmosphere [32,33]. The authors of [34] identified the Hg source of the Spilimbergo WI mostly in the incineration of hospital wastes, which accounted for $57.6 \%$ of the total material treated by the plant.

The study area has no geochemical anomalies [35] and, in parallel, the Hg content of lichen samples was never significantly correlated with $\mathrm{Al}$ (data not shown). Consequently, the significant increase of $\mathrm{Hg}$ in native X. parietina observed between 1999 (when the average value in the study area corresponded to the Italian background level) and 2007 (when some sites resulted heavily polluted, with max. values of circa $0.384 \mu \mathrm{g} \mathrm{g}^{-1}$ ), not certainly the result of soil contamination, was-Almost unavoidably - referred to the new perturbation factor present in the study area, that is, the WI, which started to operate a few months after $\mathrm{BS}_{1999}$ [36]. Overall, the magnitude of concentrations corroborated the occurrence of an important environmental pollution. In particular, by comparing the maximum $\mathrm{Hg}$ values with the threshold values of the "naturality" / alteration scales proposed by the authors of [37], the entity of $\mathrm{Hg}$ pollution was classified as "middle alteration from natural conditions", with single sites falling in the class of "maximum alteration" [36]. It is noteworthy that single concentration values were comparable to those observed in the same biomonitor from highly polluted urban and industrial areas of central Italy [38,39], northern France [40], and north-eastern Turkey [41].

In general, the statistical and geostatistical elaboration of BS data can provide reliable, accurate, and robust information, useful to evaluate the temporal changes in the distribution pattern of pollutant emissions from a punctual source only if high-density probabilistic samplings are adopted and the potential bias related to the biology of the biomonitor are taken into account. In our case study, the robustness of our geostatistical analyses (with a $500 \times 500 \mathrm{~m}$ spatial resolution; Table S2 Figure 3) is fully corroborated by the tight relationship between $\mathrm{Hg}$ content measured in biomonitor samples and the distance from the putative $\mathrm{Hg}$ source (Figure 2a). Interestingly, similar relationships were observed in lichen samples collected at increasing distance from abandoned cinnabar mining site or geothermal source placed in central Italy $[42,43]$. This is noteworthy because, although the WI plant adopted the best available technologies accordingly to IPPC legislation, $\mathrm{Hg}$ emissions persisted for 16 years with a contamination radius of $\sim 2 \mathrm{~km}$. On the other hand, the robustness of our BSs' results is supported by the high consistency of interpolation values predicted with different series of samples (i.e., $\mathrm{X}_{1} \mathrm{p}_{1999}$, $\mathrm{Xp}_{2007}, \mathrm{Pf}-\mathrm{6}_{2008}, \mathrm{Pf}-12_{2008}, \mathrm{Pf}-2_{2008}$, and Rp- $\mathrm{G}_{2014}$ ). This is an important result because, for the first time, it has been possible to demonstrate that although different biomonitors were used to detect $\mathrm{Hg}$ pollution, the spatial relationship among $\mathrm{Hg}$ content measured in biological samples collected or exposed at different sites is well-preserved also over a prolonged period of time. Nevertheless, the interpolation analyses performed on P. furfuracea samples were characterized by high values of RMSE and were partially inconsistent with the interpolation elaborated for $X_{p_{2007}}$ and Rp-G $G_{2014}$ samples (Table 4; Figure 3). This disagreement (low values of correlation in Table 4) might depend on both the different spatial structure of the dataset (i.e., the location of the sampling and exposure sites; compare Figure $1 \mathrm{~d}$ vs. Figure 1e) and the respective sampling density [44]. Certainly, the presence of astonishing extreme values in the P. furfuracea sample series, besides to impose a log-transformation of our data prior to interpolation analysis, made it difficult to find a proper variogram function without causing an over- or under-estimation of interpolation values. The reliability of interpolation methods for biomonitoring purposes have been widely discussed by the authors of [45], pointing out the 
sensitivity of these methods to the presence of outliers [46], as well as to the distribution function of the data.

\subsection{Comparison Among BSs' Results}

In both cryptogams and vascular plants, $\mathrm{Hg}$ accumulation has widely been investigated for $\mathrm{Hg}^{0}$ and only to a lesser extent for $\mathrm{Hg}^{2+}$ and $\mathrm{Hg}_{\mathrm{p}} \cdot \mathrm{Hg}^{0}$ fluxes in leaves are bi-directional, allowing a continuous exchange between air and leaves [47,48]. There are data suggesting that $\mathrm{Hg}^{0}$ accumulation in lichens is ruled by similar mechanisms [49]. Therefore, although $\mathrm{Hg}^{0}$ is not stably absorbed and accumulated onto leaves or lichen matrices over a prolonged period, high amounts of $\mathrm{Hg}$ in biological matrices inevitably reflect a continuous availability of air $\mathrm{Hg}$, as has been described for a volcanic environment, in which different taxa of both lichen and plants accumulate $\mathrm{Hg}$ in similar amounts [50]. In this study, the geostatistical comparison among the results of the five BSs clearly highlighted that the study area was affected by a well-defined and wind dependent spatial pattern of $\mathrm{Hg}$ over a period of 16 years (Figure 3). Interestingly, despite that $P$. furfuracea samples were exposed for short periods (i.e., 6, 12, and 24 weeks, respectively), some of them accumulated 10 times more $\mathrm{Hg}$ than R. pseudoacacia and $X$. parietina samples, which were exposed to the environmental conditions for longer periods of time (circa 40 and 52 weeks, respectively, see Fortuna and Tretiach 2018) (Table 2). On the other hand, our data did not allow us to provide a reliable comparison of $\mathrm{Hg}$ accumulation capabilities between the two lichen biomonitors, which were collected and exposed, respectively, in the same study area, but not at the same time-the pollution scenario between 2007 (when X. parietina was collected) and 2008 (when P. furfuracea was transplanted) might have been significantly different in terms of both rate of $\mathrm{Hg}$ emission and $\mathrm{Hg}$ content in the moieties of burned waste. However, previous laboratory experiments demonstrate that $P$. furfuracea significantly accumulates more $\mathrm{Hg}^{0}$ than X. parietina [51]. Also, in this case, the high $\mathrm{Hg}$ accumulation performance observed for $P$. furfuracea has been brought back to the isidia, that is, minute fingerlike outgrowths, with a high chlorophyll content, which considerably increase the external exchange surface of the lichen [52,53], and thus $\mathrm{CO}_{2}$ gas exchange between thallus and atmosphere. All these factors increase gross photosynthesis, which, if compared with non-isidiate species such as X. parietina, is almost two times higher [52]. In addition to improving the exchange of gaseous $\mathrm{Hg}$, isidia might also increase the entrapment of air particulate matter, with all $\mathrm{Hg}$ species eventually adsorbed to it (e.g., $\mathrm{Hg}^{2+}$ and $\mathrm{Hg}_{\mathrm{p}}$ ). Therefore, the high $\mathrm{Hg}$ content observed in P. furfuracea suggests that the main $\mathrm{Hg}$ species emitted from the WI might be $\mathrm{Hg}^{2+}$ (e.g., $\mathrm{HgCl}_{2}$ ) and $\mathrm{Hg}_{\mathrm{p}}$.

A final remark concerns the differences in terms of $\mathrm{Hg}$ content observed between green and yellow leaves of R. pseudoacacia. In accordance with what has been observed by other authors (e.g., [54]), our data pointed out that light, but significant differences in $\mathrm{Hg}$ concentration in leaves of the same plant species are mainly driven by differences in the specific leaf area (SLA). During senescence, leaves undergo progressive deterioration, connected to the dismantling of the photosynthetic apparatus with progressive reduction of photosynthesis. This implies a reduction of starch deposits, and a progressive lightening of the leaf itself [55]. Actually, SLA of yellow R. pseudoacacia leaves was higher $\left(2.06 \pm 0.46 \mathrm{~m}^{2} \mathrm{~g}^{-1}\right)$ than that of green leaves $\left(1.83 \pm 0.30 \mathrm{~m}^{2} \mathrm{~g}^{-1}\right)$. However, in proximity to the pollution source, the difference in $\mathrm{Hg}$ content of green and yellow leaves also remained high $(25 \%)$ when the data were expressed on area (compare the maximum values of $R p-G_{2014}$ and $R p-Y_{2014}$ samples in Table 1). This suggests that at high Hg air concentrations, small differences in leaf time span can become a further source of variation. However, further investigation is required before considering leaf pigmentation as a potential bias in $\mathrm{Hg}$ pollution biomonitoring.

\subsection{Effectiveness of Biomonitoring Techniques in Pollution and Monitoring Assessment Programs}

At present, in Europe, the national air monitoring networks measure the air concentrations of different $\mathrm{Hg}$ species according to highly standardized methodologies such as EN 15852:2010 for total gaseous $\mathrm{Hg}$ determination and, limited to a low number of monitoring stations, EN 15853:2010 for determining $\mathrm{Hg}^{2+}$ and $\mathrm{Hg}_{\mathrm{p}}$ concentrations in bulk deposition [4]. In order to provide a reliable 
time-integrated estimation of $\mathrm{Hg}$ distribution, the facilities have to be continuously maintained and, at the same time, the related consumables substituted [11]. The high costs associated with these ground-based measurements explain, at least in part, why across Europe, the number of air monitoring stations is low $(n=24 ;[9])$ and their temporal data coverage scarce (only $17 \%$ of monitoring stations collect more than $75 \%$ of data on an annual basis). For this reason, the European directive EC 2004 [4] suggests the implementation of less expensive, reliable alternatives in order to monitor air pollutants, $\mathrm{Hg}$ included. Indeed, it specifically encourages the use of "bioindicators where regional patterns of the impact on ecosystems are to be assessed". By exploiting the native population of cosmopolitan bioindicators, biomonitoring techniques are particularly apt to carry out preliminary, rapid investigations aimed at pinpointing potential sources of air pollutants in a given area. Our study clearly indicates that both active and passive BSs can be carried out according to high-density based sampling designs ( 1 sampling site $\mathrm{km}^{-2}$ ). This density of spatial coverage is undoubtedly out of reach for the today's air quality monitoring programs based on ground-based measurements.

Although BSs' results can be used to easily describe the spatial and temporal pattern of $\mathrm{Hg}$ emissions in a given area, a proper way to use these data in order to estimate the exact $\mathrm{Hg}$ air concentrations seems to remain a problem without a solution [56,57]. Nevertheless, in order to contextualize the magnitude of the observed pollution scenario, the results of active and passive BSs based on lichens can be expressed as a function of the species-specific background elemental content (BEC; [58-60]). This allows researchers to evaluate pollution phenomena as a relative difference between the pollutant concentrations measured in lichen samples exposed in a polluted area and those collected in unpolluted, background areas (EC ratio, see the work of [61]; now EU ratio, see the work of [60]). If these concepts would be applied to our data, we might classify the observed pollution scenario as an event causing an increase of $\mathrm{Hg}$ concentration circa 6.4, 24, and 4 times higher than the usual $\mathrm{Hg}$ content observable in the native population of X. parietina, P. furfuracea (pre-exposure values; see the work of [18]), and R. pseudoacacia, respectively. This should be the most effective way to interpret and communicate biomonitoring results to both decision makers and, most importantly, to the public. Furthermore, this way to express the results might fill the shortcomings for the implementation of active and passive biomonitoring techniques even at a legislative level.

\section{Conclusions}

The different $\mathrm{Hg}$ content in collected or exposed lichen or plant samples seems to be mainly dependent on the species-specific morpho-physiological features of biomonitors, but possibly also to their different capabilities in accumulating specific $\mathrm{Hg}$ species emitted from the pollution source.

Overall, the high accuracy of spatial distribution pattern of $\mathrm{Hg}$ should encourages the use of lichen and plant as bioaccumulators of persistent airborne pollutants in BSs and assessment programs with a threefold aim: (i) fill the shortage of data collection at local and regional scale, (ii) validate the so-called atmospheric dispersion models (ADMs) of air pollutants, and (iii) identify the most appropriate location of air quality monitoring stations (i.e., those sites subjected to the highest deposition of air pollutants).

Finally, our results clearly show that both active and passive biomonitoring surveys carried out according to highly standardized protocols are suitable tools to define whether the measured environmental changes are statistically significant. In this context, legislative organs should take into account the methodological and economic advantages inherent to the application of biomonitoring techniques.

Supplementary Materials: The following are available online at http:/ /www.mdpi.com/2073-4433/10/4/183/s1, SM1.1-SM1.3: description of sampling methodology applied in lichen and leaves sample collection, Table S1: list of SRM and CRM used in chemical analyses, Table S2: summary of setting parameters used in kriging interpolation analyses. 
Author Contributions: Conceptualization, L.F. and M.T.; methodology, L.F., F.C.C., F.C., and M.T.; formal analysis, L.F.; investigation, L.F., F.C.C., F.C., and M.T.; resources, M.T.; writing-Original draft preparation, L.F.; writing-Review and editing, M.T. and F.C.C.; visualization, L.F.; supervision, M.T.; project administration, M.T.

Funding: The researches summarized in this paper were commissioned by Provincia di Pordenone $\left(\mathrm{BS}_{1999}, \mathrm{BS}_{2007}\right)$ (sc. resp. M.T.), or were carried out in the framework of a research agreement between ARPA FVG and Department of Biology, University of Trieste $\left(\mathrm{BS}_{2008}\right)$ (sc. resp. M.T.), or received f.o.o.p. (D.T.N.) funds by M.T. $\left(\mathrm{BS}_{2014}, \mathrm{BS}_{2015}\right)$.

Acknowledgments: We warmly thank José Angel Fernández Escribano (Santiago de Compostela, Spain) for carrying out the analysis of Robinia pseudoacacia leaves of $\mathrm{BS}_{2014}$ and $\mathrm{BS}_{2015}$.

Conflicts of Interest: The authors declare no conflict of interest.

\section{References}

1. Selin, N.E. Global Biogeochemical Cycling of Mercury: A Review. Annu. Rev. Environ. Resour. 2009, 34, 43-63. [CrossRef]

2. United Nations Environment Programme. UNEP Report of the Governing Council; Twenty-Fifth Session (16-20 February 2009), General Assembly, Supplement No. 25; United Nations Environment Programme: New York, NY, USA, 2009.

3. Rafaj, P.; Bertok, I.; Cofala, J.; Schoepp, W. Scenarios of global mercury emissions from anthropogenic sources. Atmos. Environ. 2013, 79, 472-479. [CrossRef]

4. European Parliament. Directive 2004/107/EC of the European Parliament and of the Council of 15 December 2004 relating to arsenic, cadmium, mercury, nickel and polycyclic aromatic hydrocarbons in ambient air. Off. J. Eur. Communities 2004, 23, 3-16.

5. European Parliament. Directive 2008/50/EC of the European Parliament and of the Council of 21 May 2008 on ambient air quality and cleaner air for Europe. Off. J. Eur. Union 2008, 152, 1-44.

6. European Parliament. Directive 2010/75/EU of the European Parliament and of the Council of 24 November 2010 on industrial emissions (integrated pollution prevention and control). Off. J. Eur. Union 2010, 334, 17-119.

7. European Parliament. Regulation (EU) 2017/852 of the European Parliament and of the Council of 17 May 2017 on mercury, and repealing Regulation (EC) No 1102/2008. Off. J. Eur. Union 2017, 137, 1-21.

8. Pirrone, N.; Aas, W.; Cinnirella, S.; Ebinghaus, R.; Hedgecock, I.M.; Pacyna, J.; Sprovieri, F.; Sunderland, E.M. Toward the next generation of air quality monitoring: Mercury. Atmos. Environ. 2013, 80, 599-611. [CrossRef]

9. Sprovieri, F.; Pirrone, N.; Ebinghaus, R.; Kock, H.; Dommergue, A. A review of worldwide atmospheric mercury measurements. Atmos. Chem. Phys. Discuss. 2010, 10, 8245-8265. [CrossRef]

10. Wolterbeek, H.T. Biomonitoring of trace element air pollution: Principles, possibilities and perspectives. Environ. Pollut. 2002, 120, 11-21. [CrossRef]

11. Wolterbeek, H.T.; Garty, J.; Reis, M.A.; Freitas, M.C. Biomonitors in use: Lichens and metal air pollution. In Trace Metals and Other Contaminants in the Environment; Markert, B.A., Breure, A.M., Zechmeister, H.G., Eds.; Elsiever: Amsterdam, The Netherlands, 2006; Volume 6, pp. 377-419.

12. Bargagli, R. Trace Elements in Terrestrial Plants an Ecophysiological Approach to Biomonitoring and Biorecovery; Springer: Berlin, Germany, 1998.

13. Bargagli, R. Moss and lichen biomonitoring of atmospheric mercury: A review. Sci. Total Environ. 2016, 572, 216-231. [CrossRef]

14. Tretiach, M.; Adamo, P.; Bargagli, R.; Baruffo, L.; Carletti, L.; Crisafulli, P.; Giordano, S.; Modenesi, P.; Orlando, S.; Pittao, E. Lichen and moss bags as monitoring devices in urban areas. Part I: Influence of exposure on sample vitality. Environ. Pollut. 2007, 146, 380-391. [CrossRef]

15. Adamo, P.; Crisafulli, P.; Giordano, S.; Minganti, V.; Modenesi, P.; Monaci, F.; Pittao, E.; Tretiach, M.; Bargagli, R. Lichen and moss bags as monitoring devices in urban areas. Part II: Trace element content in living and dead biomonitors and comparison with synthetic materials. Environ. Pollut. 2007, 146, 392-399. [CrossRef]

16. Giordano, S.; Adamo, P.; Monaci, F.; Pittao, E.; Tretiach, M.; Bargagli, R. Bags with oven-dried moss for the active monitoring of airborne trace elements in urban areas. Environ. Pollut. 2009, 157, 2798-2805. [CrossRef] 
17. De Nicola, F.; Spagnuolo, V.; Baldantoni, D.; Sessa, L.; Alfani, A.; Bargagli, R.; Monaci, F.; Terracciano, S.; Giordano, S. Improved biomonitoring of airborne contaminants by combined use of holm oak leaves and epiphytic moss. Chemosphere 2013, 92, 1224-1230. [CrossRef]

18. Tretiach, M.; Candotto Carniel, F.; Loppi, S.; Carniel, A.; Bortolussi, A.; Mazzilis, D.; Del Bianco, C. Lichen transplants as a suitable tool to identify mercury pollution from waste incinerators: A case study from NE Italy. Environ. Monit. Assess. 2011, 175, 589-600. [CrossRef]

19. Bargagli, R. Guidelines for the Use of Epiphytic Lichens as Biomonitors of Atmospheric Deposition of Trace Elements; Springer Nature: Basingstoke, UK, 2002; pp. 295-299.

20. Petruzzellis, F.; Palandrani, C.; Savi, T.; Alberti, R.; Nardini, A.; Bacaro, G. Sampling intraspecific variability in leaf functional traits: Practical suggestions to maximize collected information. Ecol. Evol. 2017, 7, 11236-11245. [CrossRef] [PubMed]

21. Tao, S. Kriging and mapping of copper, lead, and mercury contents in surface soil in Shenzhen area. Water Air Soil Pollut. 1995, 83, 161-172. [CrossRef]

22. Heuvelink, G.B.; Pebesma, E.J. Is the ordinary kriging variance a proper measure of interpolation error. In Proceedings of the Fifth International Symposium on Spatial Accuracy Assessment in Natural Resources and Environmental Sciences, Melbourne, Australia, 10-12 July 2002; pp. 179-186.

23. Gong, G.; Mattevada, S.; O'Bryant, S.E. Comparison of the accuracy of kriging and IDW interpolations in estimating groundwater arsenic concentrations in Texas. Environ. Res. 2014, 130, 59-69. [CrossRef]

24. Fortuna, L.; Tretiach, M. Effects of site-specific climatic conditions on the radial growth of the lichen biomonitor Xanthoria parietina. Environ. Sci. Pollut. Res. 2018, 25, 34017-34026. [CrossRef]

25. Keresztesi, B. Breeding and cultivation of black locust, Robinia pseudoacacia, in Hungary. For. Ecol. Manag. 1983, 6, 217-244. [CrossRef]

26. Giordano, S.; Adamo, P.; Sorbo, S.; Vingiani, S. Atmospheric trace metal pollution in the Naples urban area based on results from moss and lichen bags. Environ. Pollut. 2005, 136, 431-442. [CrossRef] [PubMed]

27. Petrova, S. Lichen-Bags as a Biomonitoring Technique in an Urban Area. Appl. Ecol. Environ. Res. 2015, 13, 915-923. [CrossRef]

28. Protano, C.; Owczarek, M.; Antonucci, A.; Guidotti, M.; Vitali, M. Assessing indoor air quality of school environments: Transplanted lichen Pseudevernia furfuracea as a new tool for biomonitoring and bioaccumulation. Environ. Monit. Assess. 2017, 189, 358. [CrossRef] [PubMed]

29. Cocozza, C.; Ravera, S.; Cherubini, P.; Lombardi, F.; Marchetti, M.; Tognetti, R. Integrated biomonitoring of airborne pollutants over space and time using tree rings, bark, leaves and epiphytic lichens. For. Green. 2016, 17, 177-191. [CrossRef]

30. Pacyna, E.; Pacyna, J.; Sundseth, K.; Munthe, J.; Kindbom, K.; Wilson, S.; Steenhuisen, F.; Maxson, P. Global emission of mercury to the atmosphere from anthropogenic sources in 2005 and projections to 2020. Atmos. Environ. 2010, 44, 2487-2499.

31. Costa, P.; Pacyna, J.; Pirrone, N.; Ferrara, R. Mercury emissions to the atmosphere from natural and anthropogenic sources in the Mediterranean region. Atmos. Environ. 2001, 35, 2997-3006.

32. Cinnirella, S.; Finkelman, R.B.; Leaner, J.; Mukherjee, A.B.; Stracher, G.B.; Telmer, K.; Pirrone, N.; Feng, X.; Friedli, H.R.; Mason, R.; et al. Global mercury emissions to the atmosphere from anthropogenic and natural sources. Atmos. Chem. Phys. Discuss. 2010, 10, 5951-5964.

33. Mukherjee, A.B.; Zevenhoven, R.; Brodersen, J.; Hylander, L.D.; Bhattacharya, P. Mercury in waste in the European Union: Sources, disposal methods and risks. Resour. Conserv. Recycl. 2004, 42, 155-182. [CrossRef]

34. Canciani, L. Relazione Annuale Relative al Funzionamento ed alla Sorveglianza Dell'impianto di Coincenerimento e Termovalorizzazione di Rifiuti Speciali Pericolosi e non Pericolosi sito in zona Industriale del Cosa in Comune di Spilimbergo; Mistral FVG S.r.L: Spilimbergo, Italy, 2008.

35. Cerovac, A.; Covelli, S.; Emili, A.; Pavoni, E.; Petranich, E.; Gregorič, A.; Urbanc, J.; Zavagno, E.; Zini, L. Mercury in the unconfined aquifer of the Isonzo/Soča River alluvial plain downstream from the Idrija mining area. Chemosphere 2018, 195, 749-761.

36. Tretiach, M.; Pittao, E. Biomonitoraggio di Metalli Mediante Licheni in Cinque aree Campione della Provincia di Pordenone. Stato attuale e Confronto con i dati del 1999; Provincia di Pordenone: Pordenone, Italy, 2008.

37. Nimis, P.L.; Bargagli, R. Linee-guida per l'utilizzo di licheni epifiti come bioaccumulatori di metalli in traccia. In Proceedings of the Atti del Workshop Biomonitoraggio della qualità dell'aria sul territorio nazionale, Roma, Italy, 26-27 November 1998; pp. 279-289. 
38. Scerbo, R.; Possenti, L.; Lampugnani, L.; Ristori, T.; Barale, R.; Barghigiani, C. Lichen (Xanthoria parietina) biomonitoring of trace element contamination and air quality assessment in Livorno Province (Tuscany, Italy). Sci. Total Environ. 1999, 241, 91-106. [CrossRef]

39. Scerbo, R.; Ristori, T.; Possenti, L.; Lampugnani, L.; Barale, R.; Barghigiani, C. Lichen (Xanthoria parietina) biomonitoring of trace element contamination and air quality assessment in Pisa Province (Tuscany, Italy). Sci. Total Environ. 2002, 286, 27-40. [CrossRef]

40. Cuny, D.; Davranche, L.; Thomas, P.; Kempa, M.; Van Haluwyn, C.; Haluwyn, C. Spatial and Temporal Variations of Trace Element Contents in Xanthoria Parietina Thalli Collected in a Highly Industrialized Area in Northern France as an Element for a Future Epidemiological Study. J. Atmos. Chem. 2004, 49, 391-401. [CrossRef]

41. Demiray, A.D.; Yolcubal, I.; Akyol, N.H.; Çobanoğlu, G. Biomonitoring of airborne metals using the lichen Xanthoria parietina in Kocaeli Province, Turkey. Ecol. Indic. 2012, 18, 632-643. [CrossRef]

42. Bargagli, R.; Barghigiani, C.; Siegel, B.; Siegel, S. Accumulation of mercury and other metals by the lichen, Parmelia sulcata, at an italian minesite and a volcanic area. Water Air Soil Pollut. 1989, 45, 315-327. [CrossRef]

43. Loppi, S.; Paoli, L.; Gaggi, C. Diversity of epiphytic lichens and Hg contents of Xanthoria parietina thalli as monitors of geothermal air pollution in the Mt. Amiata area (central Italy). J. Atmos. Chem. 2006, 53, 93-105. [CrossRef]

44. Ferretti, M.; Brambilla, E.; Brunialti, G.; Fornasier, F.; Mazzali, C.; Giordani, P.; Nimis, P. Reliability of different sampling densities for estimating and mapping lichen diversity in biomonitoring studies. Environ. Pollut. 2004, 127, 249-256. [CrossRef]

45. Aboal, J.R.; Real, C.; Fernández, J.A.; Carballeira, A. Mapping the results of extensive surveys: The case of atmospheric biomonitoring and terrestrial mosses. Sci. Total Environ. 2006, 356, 256-274. [CrossRef] [PubMed]

46. Real, C.; Aboal, J.; Fernandez, J.A.; Carballeira, A.; Aboal, J. The use of native mosses to monitor fluorine levels-And associated temporal variations-In the vicinity of an aluminium smelter. Atmos. Environ. 2003, 37, 3091-3102. [CrossRef]

47. Hanson, P.J.; Lindberg, S.E.; Tabberer, T.A.; Owens, J.G.; Kim, K.-H. Foliar Exchange of Mercury Vapor: Evidence for a Compensation Point. Water Air Soil Pollut. 1995, 80, 373-382. [CrossRef]

48. Millhollen, A.G.; Gustin, M.S.; Obrist, D. Foliar Mercury Accumulation and Exchange for Three Tree Species. Environ. Sci. Technol. 2006, 40, 6001-6006. [CrossRef] [PubMed]

49. Walther, D.A.; Ramelow, G.J.; Beck, J.N.; Young, J.C.; Callahan, J.D.; Maroon, M.F. Temporal changes in metal levels of the lichens Parmotrema praesorediosum and Ramalina stenospora, southwest Louisiana. Water Air Soil Pollut. 1990, 53, 189-200. [CrossRef]

50. Barghigiani, C.; Bargagli, R.; Siegel, B.; Siegel, S. Source and selectivity in the accumulation of mercury and other metals by the plants of Mt. Etna. Water Air Soil Pollut. 1988, 39, 395-408.

51. Vannini, A.; Nicolardi, V.; Bargagli, R.; Loppi, S. Estimating Atmospheric Mercury Concentrations with Lichens. Environ. Sci. Technol. 2014, 48, 8754-8759. [CrossRef] [PubMed]

52. Tretiach, M.; Crisafulli, P.; Pittao, E.; Rinino, S.; Roccotiello, E.; Modenesi, P. Isidia ontogeny and its effect on the $\mathrm{CO}_{2}$ gas exchanges of the epiphytic lichen Pseudevernia furfuracea (L.) Zopf. Lichenologist 2005, 37, 445-462. [CrossRef]

53. Honegger, R. Developmental biology of lichens. New Phytol. 1993, 125, 659-677. [CrossRef]

54. Rea, A.W.; Lindberg, S.E.; Scherbatskoy, T.; Keeler, G.J. Mercury Accumulation in Foliage over Time in Two Northern Mixed-Hardwood Forests. Water Air Soil Pollut. 2002, 133, 49-67. [CrossRef]

55. Lindroth, R.; Osier, T.; Barnhill, H.; Wood, S. Effects of genotype and nutrient availability on phytochemistry of trembling aspen (Populus tremuloides Michx.) during leaf senescence. Biochem. Syst. Ecol. 2002, 30, 297-307. [CrossRef]

56. Aboal, J.; Fernandez, J.A.; Boquete, T.; Carballeira, A.; Aboal, J.; Boquete, M.T. Is it possible to estimate atmospheric deposition of heavy metals by analysis of terrestrial mosses? Sci. Total Environ. 2010, 408, 6291-6297. [CrossRef] [PubMed]

57. Schröder, W.; Holy, M.; Pesch, R.; Harmens, H.; Ilyin, I.; Steinnes, E.; Alber, R.; Aleksiayenak, Y.; Blum, O.; Coşkun, M.; et al. Are cadmium, lead and mercury concentrations in mosses across Europe primarily determined by atmospheric deposition of these metals? J. Soils Sediments 2010, 10, 1572-1584. [CrossRef] 
58. Incerti, G.; Cecconi, E.; Capozzi, F.; Adamo, P.; Bargagli, R.; Benesperi, R.; Carniel, F.C.; Cristofolini, F.; Giordano, S.; Puntillo, D.; et al. Infraspecific variability in baseline element composition of the epiphytic lichen Pseudevernia furfuracea in remote areas: Implications for biomonitoring of air pollution. Environ. Sci. Pollut. Res. 2017, 24, 8004-8016. [CrossRef]

59. Cecconi, E.; Incerti, G.; Capozzi, F.; Adamo, P.; Bargagli, R.; Benesperi, R.; Carniel, F.C.; Favero-Longo, S.E.; Giordano, S.; Puntillo, D.; et al. Background element content of the lichen Pseudevernia furfuracea: A supra-national state of art implemented by novel field data from Italy. Sci. Total Environ. 2018, 622, 282-292. [CrossRef] [PubMed]

60. Cecconi, E.; Fortuna, L.; Benesperi, R.; Bianchi, E.; Brunialti, G.; Contardo, T.; Di Nuzzo, L.; Frati, L.; Monaci, F.; Munzi, S.; et al. New Interpretative Scales for Lichen Bioaccumulation Data: The Italian Proposal. Atmosphere 2019, 10, 136. [CrossRef]

61. Frati, L.; Brunialti, G.; Loppi, S. Problems Related to Lichen Transplants to Monitor Trace Element Deposition in Repeated Surveys: A Case Study from Central Italy. J. Atmos. Chem. 2005, 52, 221-230. [CrossRef]

(C) 2019 by the authors. Licensee MDPI, Basel, Switzerland. This article is an open access article distributed under the terms and conditions of the Creative Commons Attribution (CC BY) license (http:// creativecommons.org/licenses/by/4.0/). 